\title{
Senate passes Animal Enterprise Terrorism Act
}

On 30 September 2006, the Senate passed by unanimous consent S. 3880, the "Animal Enterprise Terrorism Act.” The Act will "provide the Department of Justice the necessary authority to apprehend, prosecute, and convict individuals committing animal enterprise terror ${ }^{1}$." This bill will next be addressed in the House of Representatives.

If enacted, the Act will amend Section 43 of title 18 of the United States Code to cover violence and threats involving animal enterprises perpetrated by

whoever travels in interstate or foreign commerce, or uses or causes to be used the mail or any facility of interstate or foreign commerce... for the purpose of damaging or interfering with the operations of an animal enterprise; and
(A) intentionally damages or causes the loss of any real or personal property (including animals or records) used by an animal enterprise, or any real or personal property of a person or entity having a connection to, relationship with, or transactions with an animal enterprise;

(B) intentionally places a person in reasonable fear of the death of, or serious bodily injury to that person, a member of the immediate family... of that person, or a spouse or intimate partner of that person by a course of conduct involving threats, acts of vandalism, property damage, criminal trespass, harassment, or intimidation; or

(C) conspires or attempts to do $\mathrm{so}^{1}$.
Violators of this act will be punished based on an escalating scale. Minor offenses - those that do not instill in another person reasonable fear of serious bodily harm or death-may result in a fine and/or imprisonment of not more than one year. More serious offenses, such as those that cause serious bodily injury to another individual or economic damage exceeding \$1 million, may be punished by a jail term of up to 20 years, a fine, or both. Life imprisonment is the maximum penalty and may be considered in cases in which the offense results in the death of another individual.

1. S. 3880. 'Animal Enterprise Terrorism Act' (28 September 2006).

\section{New ACLAM guidelines on rodent and rabbit pain}

In July 2006, the board of the American College for Laboratory Animal Medicine (ACLAM) approved its "Guidelines for the Assessment and Management of Pain in Rodents and Rabbits ${ }^{1}$." This new report "presents an overview of current concepts of pain and provides recommendations for the assessment, prevention and treatment of pain in rodents and rabbits ${ }^{1}$." In addition, it provides "guidelines for developing pain management protocols, and tables describing the potential physiologic effects of some analgesic classes and examples of efficacious analgesic strategies ${ }^{1}$."

Among the topics in this report are definitions of pain and related terms; physiologi- cal basis of pain perception; pain-management strategies, including pharmacological and nonpharmacological considerations; and pain-assessment methods.

1. ACLAM. Guidelines for the Assessment and Management of Pain in Rodents and Rabbits. http://www.aclam.org/PDF/pub_pain_rod_rab2006-07.pdf.

\section{OLAW publishes guidance for IACUCs and investigators}

\section{FAQ website}

The Office of Laboratory Animal Welfare (OLAW) has recently posted a compilation of frequently asked questions (FAQs) online ${ }^{1}$. The purpose of the new page is to provide up-to-date guidance for institutions and IACUCs to use in implementing the Public Health Service Policy on Humane Care and Use of Laboratory Animals (PHS Policy). Many of the answers refer to guidance previously published as articles in journals and magazines, such as Contemporary Topics in Laboratory
Animal Science (now JAALAS) and Lab Animal. The new FAQs provide guidance on the Freedom of Information Act, postapproval monitoring, HVAC malfunctions and failures, rodent cage density, and other issues not previously addressed by OLAW.

\section{Brochure for investigators}

In addition, OLAW has created a brochure entitled, "What Investigators Need to Know About the Use of Animals"," to educate investigators about their respon- sibilities under PHS Grants Policy and PHS Policy." This brochure, available on the web and in hard copy from OLAW, describes the expectations and requirements when using animals in research supported by the PHS.

1. OLAW. PHS Policy on Humane Care and Use of Laboratory Animals: Frequently Asked Questions (11 September 2006). http://grants.nih.gov/ grants/olaw/faqs.htm.

2. OLAW. What Investigators Need to Know About the Use of Animals. http://grants.nih.gov/ grants/olaw/InvestigatorsNeed2Know.pdf. 